\title{
ANÁLISE DE ACIDENTES DE TRABALHO COM MATERIAL BIOLÓGICO ENTRE OS PROFISSIONAIS DO HOSPITAL SÃO JOÃO BATISTA, NO ANO DE 2014
}

\begin{abstract}
Juliane Salvaro Pavan
Engenheira Civil, Universidade do Extremo Sul Catarinense, julianesalvaro@bol.com.br Daiani Bortolotto Picolo Acadêmica do Curso de Fisioterapia, Universidade do Extremo Sul Catarinense, daigre7@gmail.com Ricardo Martins Saibt Mestrando em Saúde Coletiva, Universidade do Extremo Sul Catarinense, ricardosaibt@gmail.com Willians Cassiano Longen Doutor, Universidade do Extremo Sul Catarinense, willians@unesc.net
\end{abstract}

\section{RESUMO}

Os acidentes de trabalho ocasionados por material biológico, entre os profissionais da área da saúde, apresentam altos índices de incidências. São classificados de grande risco, pois podem ocasionar a transmissão doenças infectocontagiosas. Este trabalho foi desenvolvido para conscientizar os profissionais, alertando-os a realizar uma reflexão dos indicadores (ANVISA, 2003). Diante disso, este trabalho procurou analisar as ocorrências de acidentes de trabalho com material biológico, entre os profissionais da saúde atuantes no Hospital São João Batista 
(HSJB), de Criciúma (SC), no ano de 2014, além de identificar as principais causas dos acidentes com material biológico e analisar a frequência dos acidentes, bem como arranjar e analisar os dados das Comunicaçóes de Acidente de Trabalho (CAT) ocorridos com material biológico. A amostra do estudo em questáo foi formada por profissionais da saúde (excluindo-se os funcionários terceirizados) do HSJB que tiveram a CAT registrada no Serviço Especializado em Engenharia de Segurança e Medicina do Trabalho (SESMT), durante o ano de 2014. É importante destacar que foram analisados apenas os acidentes com material biológico. Identificou-se que 202 funcionários eram do sexo feminino $(81,45 \%)$ e 46 do sexo masculino (18,55\%). Observou-se, no decorrer da análise, que os meses de julho e agosto de 2014 tiveram o maior número de acidentes registrados. Constatou-se ainda que o setor com o maior número de ocorrências de acidentes com material biológico foi o Centro Cirúrgico, com 14 registros (60,87\% dos acidentes). A função que mais incorreu em acidentes do trabalho foi a de técnico em enfermagem, com 22 registros $(95,65 \%)$. A faixa etária dos funcionários mostrou que $9(39,13 \%)$ dos registros da CAT foram de 21 a 30 anos e $14(60,87 \%)$ ocorreram na faixa etária de 31 a 40 anos. No período de 2 a 4 horas de serviço, foram ao todo $9(39,13 \%)$ registros. O local do corpo onde os acidentes foram notificados correspondeu a $16(69,60 \%)$ casos no dedo, dos quais $47,82 \%$ foram causados por agulha. Material biológico: sangue (91,30\%). Os resultados obtidos, quanto à atividade exercida no momento do acidente, estáo intimamente ligados ao local com maior ocorrência dos mesmos (centro cirúrgico). Dessa forma, os procedimentos cirúrgicos foram os mais apontados, com $35 \%$ dos casos.

Palavras-Chave: Acidentes de Trabalho; Material Biológico; Segurança no Trabalho.

\section{REFERÊNCIAS}

ANVISA. Segurança no ambiente hospitalar. Brasília: 2003. Disponível em: <http://novoportal.anvisa.gov.br/documents/33852/271855/Seguran\%C3\%A7a+no+ambiente+hospitalar/473c5e32-025a-4dc2-ab2e-fb5905d7233a>. Acesso em: 15 mar. 2016. 